\title{
A CALAGEM NOS TEORES DE ÓLEO E PROTEÍNA EM SOJA ( ${ }^{1}$ )
}

\author{
HIPÓLITO ASSUNÇĀO ANTONIO MASCARENHAS $(2,7)$, JOÄO PAULO FEIJÄO \\ TEIXEJRA (3, 7), VIOLETA NAGAI (4), ROBERTO TETSUO TANAKA $(2,7)$, \\ PAULO BOLLER GALLO (5) e JOSÉ CARLOS VILA NOVA ALVES PEREIRA (6)
}

\begin{abstract}
RESUMO
No ano agrícola de 1986/87, nas Estaçōes Experimentais de Mococa e Ribeirão Preto, efetuaram-se experimentos com o objetivo de avaliar o efeito da aplicaçăo de níveis crescentes de calcário dolomítico $(0,4,8$ e 12t/ha) sobre os teores de óleo e proteína nos grãos dos cultivares de soja IAC-Foscarin-31, IAC-11, IAC-12 e Cristalina. Os maiores teores de 6leo e de proteína foram observados nos grãos colhidos em Mococa. Independentemente da calagem e das localidades, O 'IAC-12' apresentou as maiores produçőes médias de óleo e proteina por área, 561 e $963 \mathrm{~kg} / \mathrm{ha}$ respectivamente. Em todas as localidades, a calagem promoveu a elevação do teor de proteina e a redução do teor de óleo nos grăos. A produção de óleo e proterna (kg/ha) aumentou linearmente com os niveis de calagem utilizados, em decorrência de significativo aumento do rendimento em grăos após a correção do solo.
\end{abstract}

Termos de indexaçáo: soja, calagem, óleo, proteína.

\section{ABSTRACT \\ LIMING ON THE CONCENTRATION OF OIL AND PROTEIN IN SOYBEANS}

During the year 1986/87, experiments were conducted at the Experiment Stations of Mococa and Ribeirăo Preto in the State of Săo Paulo, Brazil. The objective was to evaluate the effect of four rates of lime $(0,4,8$

(1) Recebido para publicaçăo em 16 de outubro de 1989 e aceito em 22 de fevereiro de 1990. Trabalho parcialmente financiado pela FAPESP - Processo 88/3876-0.

(2) Seçăo de Leguminosas, Instituto Agronómico (IAC), Caixa Postal 28, 13001 Campinas, SP.

(3) Seção de Fitoquínica, IAC.

(4) Seçăo de Técnica Experimental e Cálculo, IAC.

(5) Estaçăo Experimental de Mococa, IAC.

(6) Estaçăo Experimental de Ribeirăo Preto, IAC.

(7) Com bolsa de pesquisa do CNPq. 
and $12 \mathrm{t} / \mathrm{ha}$ ) on the concentrations of oil and protein in the seeds of the following soybean cultivars: IAC-Foscarin-31, IAC-11, IAC-12, and Cristalina. The maturity group varied from 130 to 160 days. The results showed that highest concentration of oil and protein was observed in seeds harvested at Mococa. Independently of liming and locality the cultivar IAC-12 presented the highest average production of oil and protein per area (561 and $963 \mathrm{~kg} / \mathrm{ha}$, respectively). In both experiments, addition of lime resulted in raise of seed protein but in consistent decrease of seed oil for all cultivars. The quantity of oil and protein per area increased linearly with the increase in the rates of lime. This occurred as a result of the increase in seed yield after reducing soil acidity.

Index terms: soybean cultivars, liming, oil, protein.

\section{INTRODUÇÃo}

Em estudos com diferentes cultivares de soja, TANGO et al. (1974a, 1974 b) verificaram uma variação nos teores de óleo e de proteína nas sementes, conforme a localidade do cultivo e o ano agrícola. Resultados semelhantes foram observados por TEIXEIRA et al. (1979a) e MAINI \& BAINS (1965). Em estudos nos EUA, HARTWG (1973) constatou teores médios de proteína éleo de 40,5 e $21 \%$ respectivamente, enquanto, no Estado de São Paulo, MASCARENHAS (dados não publicados) observou para essas substâncias de reserva na semente valores de 35 e $24 \%$ respectivamente. As diferenças nos teores de óleo e de proteina entre cultivares recomendados no Brasil e nos EUA provavelmente sejam devidas a fatores ambientais, destacando-se a acidez do solo. Razóes genéticas podem ser descartadas, pois, de acordo com HIROMOTO \& VELLO (1986), os cultivares recomendados nos dois paises tem bases genéticas semeihantes.

Trabalhando com outros cultivares de soja, TANGO et al. (1974c) não encontraram diferenças nos teores de proteina e de óleo pela aplicação de nitrogênio mineral, inoculantes, calagem e adubação mineral. TEIXEIRA et al.(1979b) confirmaram esses dados, mostrando que a aplicação de níveis crescentes de fósforo e de potássio não proporcionou aumento dos teores de proteína no cultivar Santa Rosa. Por outro lado, os trabalhos de MAINI \& BAINS (1965) e de MURSE (1959) revelaram a influência da adubação mineral sobre a composição química de sementes de soja. Pesquisas mais recentes, de MASCARENHAS et al. (1982) e GALLO et al. (1986), evidenciaram que, com o aumento de niveis de calagem, eleva-se o teor de nitrogênio das folhas pela maior eficiência da fixaçāo simbiótica e, conseqüentemente, a proteína nas sementes.

O objetivo deste trabalho foi avaliar o efeito da aplicação de níveis crescentes de calcário nos teores de óleo e proteína de sementes de quatro cultivares de soja de diferentes ciclos., 


\section{MATERIAL E MÉTODOS}

Utilizaram-se sementes de soja dos cultivares IAC-Foscarin-31 (ciclo precoce), IAC-12 (semiprecoce), IAC-11 (médio) e Cristalina (semitardio) provenientes de ensaios de calagem do ano agricola $1986 / 87$, realizados nas Estaçōes Experimentais de Mococa e de Ribeirāo Preto, em podzólico vermelho-amarelo orto e latossolo-roxo distrófico respectivamente. Os experimentos foram delineados em blocos ao acaso com parcelas subdividadas e quatro repetiçōes. Os tratamentos das parcelas principais corresponderam a aplicaçöes de $0,4,8$ e 12t/ha de calcário dolomítico; nas subparcelas, semearam-se os quatro cultivares de soja. A adubação aplicada na semeadura foi de $400 \mathrm{~kg} / \mathrm{ha}$ da fórmula 0-25-15. Após a colheita, trituraram-se as amostras de sementes em moinho, 40 mesh, e determinaram-se os teores de proteína e de óleo.

Para a determinação do teor de proteína, avaliou-se inicialmente o de nitrogênio total pelo método Kjeldahl, o qual foi multiplicado pelo fator 6,25 (TEIXEIRA, 1984).

O teor de óleo foi determinado gravimetricamente após lavagem exaustiva das amostras com solvente orgânico, hexano, a quente, em extratores soxhlet (TEIXEIRA et al., 1984).

Para a análise do efeito da calagem, utilizaram-se polinômios ortogonais e, na comparação de médias de cultivares, empregou-se o teste de Duncan ao nivel de $5 \%$.

\section{RESULTADOS E DISCUSSÃO}

No quadro 1 encontram-se os teores de óleo e proteína em sementes de soja referentes ao ensaio de Mococa. Na ausência de calagem, o índice de saturação por bases no solo foi de $37 \%, 0$ que resulta em menor fixaçăo do nitrogê nio pelo Bradyrhizobium, devido a condiçōes adversas, como acidez elevada e deficiência de cálcio e magnésio no solo. Neste caso, como há correlação negativa entre os teores de óleo e de proteína, os grăos de soja apresentam maior teor de óleo, conforme observado por MASCARENHAS et al. (1982); essa observação é discordante daquela de TANGO et al. (1974c). Os cultivares Cristalina e IAC-Foscarin-31 atingiram os teores mais elevados de óleo, seguidos por IAC-11 e IAC-12. Com a aplicação de 4, 8 e 12t/ha de calcário, os índices de saturação por bases elevaram-se, atingindo 53,60 e $72 \%$ respectivamente. As condiçбes se tornaram cada vez mais favoráveis à fixação de nitrogênio; conseqüentemente, observaram-se decréscimos nos teores de óleo. Isso foi evidenciado para os quatro cultivares, com o componente linear negativo e significativo, sendo a maior reduçăo no 'IAC-Foscarin-31' e 'Cristalina', seguidos por 'IAC-11' e 'IAC-12'. Em média, independente dos niveis de calagem aplicados, 'Cristalina' apresentou o maior teor em óleo, seguido pelo 'IAC-Foscarin-31'; os cultivares IAC-11 e IAC-12 não diferiram entre si. $O$ decréscimo linear no teor de óleo, pela aplicaçăo de calagem, independente do efeito de cultivares, pode ser observado na figura 1. 


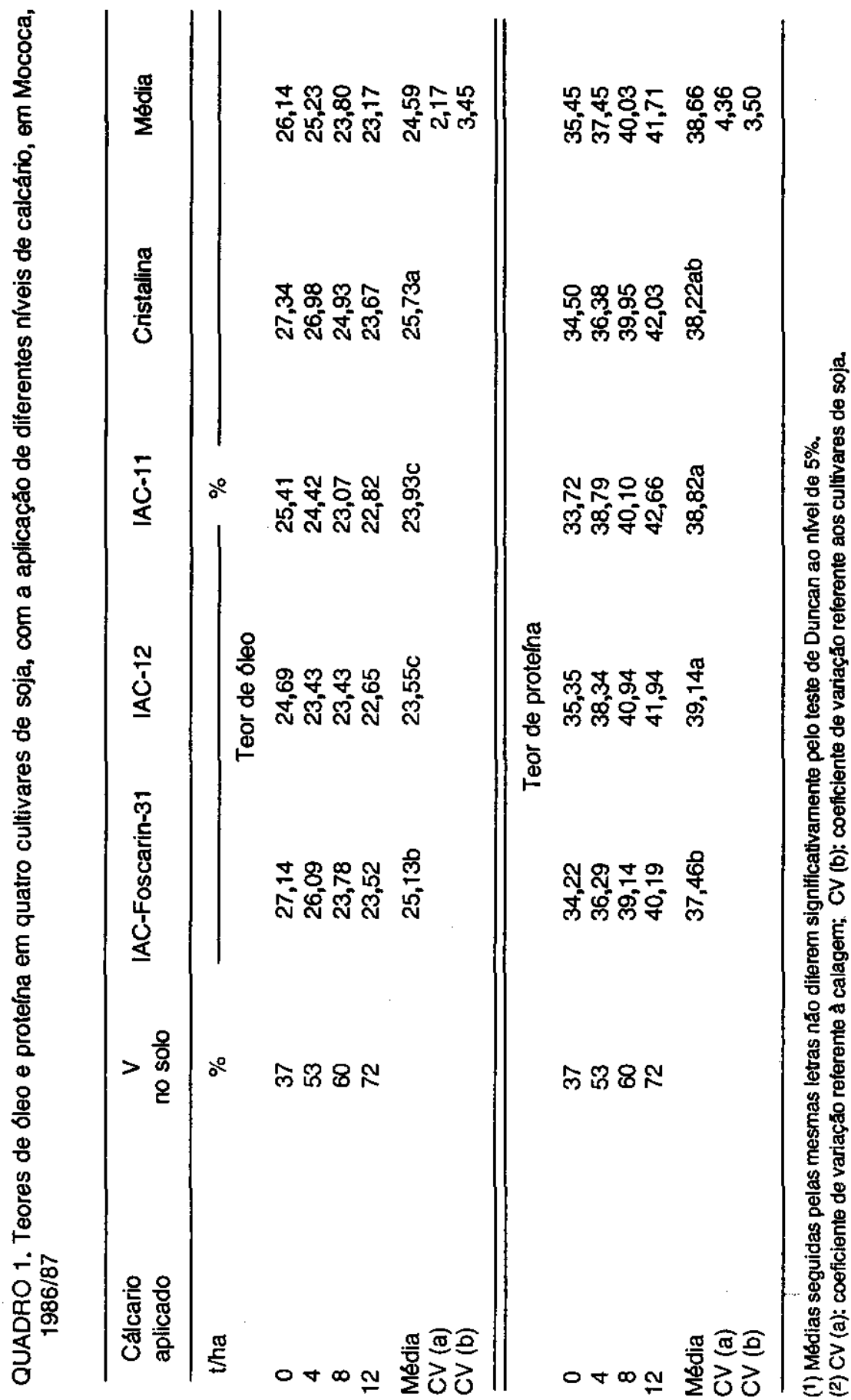




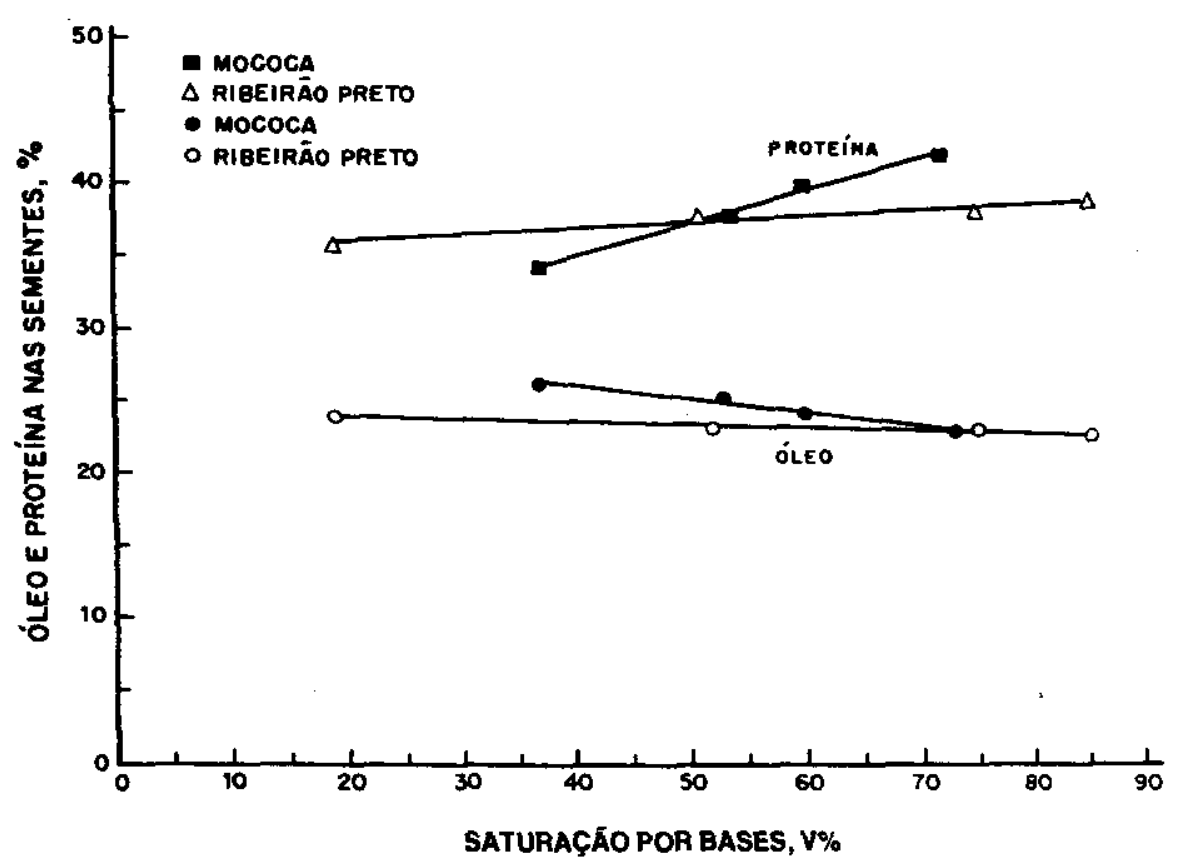

FIGURA 1. Teor percentual de óleo e proteina nas sementes de soja em função do Indice de saturaçáo por bases.

Com o aumento do indice de saturação por bases em funçāo dos niveis de calagem, obtém-se redução da acidez do solo e melhor fixação de nitrogênio pelo Bradyrhizobium e formação de maior quantidade de nódulos. GALLO et al. (1986) verificaram que, com a elevação do indice de saturação por bases pela aplicação de calcário, cresceu o teor de nitrogênio das folhas, contribuindo para maior concentração de proteína nos grãos. Essa relação direta também se observa no presente trabalho para todos os cultivares (Quadro 1). Além do efeito benéfico da calagem, contribuindo para melhorar as condiçōes para a fixação biológica do nitrogênio atmosférico, o aumento da disponibilidade do molibdênio por esta prática acarreta a sua maior absorção pelos tecidos vegetais. Dessa forma, sendo o molibdênio um dos componentes da enzima redutase do nitrato, sua presença em maior teor proporciona a formação de mais aminoácidos e, conseqüentemente, de proteinas. O maior teor de proteína foi obtido com o maior índice de saturação por bases (V\% 72): 42,66\% para o 'IAC-11', 42,03\% para o 'Cristalina', $41,94 \%$ para o 'IAC-12' e 40,19\% para o 'IAC-Foscarin-31'. Independente dos niveis de calagem, os teores médios de proteína do 'IAC-12' e 'IAC-11', sem diferirem entre si, e do 'Cristalina', foram mais elevados do que os do 'IAC.Foscarin-31'. Na figura 1, nota-se que, com aumento do índice de saturação por bases, 
em Mococa, há um aumento médio em torno de $6 \%$ no teor de proteina dos cultivares.

Em Ribeirāo Preto (Quadro 2), os dados obtidos assemelham-se àqueles de Mococa - Quadro 1. O decréscimo no teor de óleo e o aumento no de proteína são menores do que os obtidos em Mococa (Figura 1), possivelmente devido ao tipo do solo e clima, confirmando TANGO et al. (1974a,b) e TEIXEIRA et al. (1979a,b). Para as duas localidades, há diferenças entre as médias nos teores de óleo e de proteína entre os cultivares; entretanto, somente em relação à proteína, manteve-se a mesma ordem, isto é 'IAC-11' e 'IAC-12' foram os de maior teor nas duas localidades. Isso vem indicar que o efeito da interação entre genótipo e locais é mais forte sobre o teor de óleo do que sobre o de proteína. Os teores médios de óleo e proteína são maiores em Mococa do que em Ribeirão Preto.

Nesse estudo, observa-se também que os cultivares IAC-11 e IAC-12 apresentam maior relaçăo proteína/óleo do que IAC-Foscarin-31 e Cristalina Quadro 3. No entanto, Hartwig, citado por PORTO (1983), obteve valores bem superiores dessa relação, devido, sobretudo, ao melhoramento genético direcionado para elevação do teor de proteina.

A produção de óleo ou proteina por unidade de área é muito mais relevante do que o teor "per se" e depende do potencial de produçáo de cada genótipo. Através desse parâmetro, pode-se verificar que, nas duas localidades, apesar do decréscimo no teor de óleo pelo aumento do índice de saturação por bases, houve um aumento linear, significativo, na produtividade de óleo - Figura 2.

$\mathrm{Na}$ ausência de calagem, o rendimento em grãos dos cultivares foi menor devido à acidez do solo, que se refletiu na produtividade de grãos. O mais sensivel entre os cultivares foi o IAC-11, que produziu apenas 274 e $276 \mathrm{~kg} / \mathrm{ha}$ de óleo, respectivamente, em Mococa e Ribeirão Preto - Quadros 4 e 5.

De modo geral, o 'IAC-12' apresentou as maiores produtividades de óleo e proteina, independente dos niveis de calagem, exceto na dose de 4t/ha de calcário, no experimento de Ribeirão Preto, no qual o cultivar IAC-Foscarin-31 mostrou maior rendimento de óleo.

Pela figura 2, observa-se um aumento linear na quantidade de óleo e proteína produzida $(\mathrm{kg} / \mathrm{ha}) \mathrm{com}$ aumento do indice de saturação por bases. MASCARENHAS et al. (1982) obtiveram $1.264 \mathrm{~kg} / \mathrm{ha}$ de proteina e $574 \mathrm{~kg} / \mathrm{ha}$ de óleo com a aplicação de 8tha de calcário no 'IAC-8'. No presente trabalho, com 12t/ha de calcário, em Ribeirăo Preto, foram obtidos 1.066, 1.277, 1.300 e $1.120 \mathrm{~kg} / \mathrm{ha}$ de proteína, e $653,701,706$ e $617 \mathrm{~kg} / \mathrm{ha}$ de 6 leo, respectivamente, para os cultivares IAC-Foscarin-31, IAC-12, IAC-11 e Cristalina (Quadro 5). Através do melhoramento genético, Hartwig, citado por PORTO (1983), obteve a linhagem D76.8338, com $46 \%$ de proteina e $18 \%$ de óleo, e que produziu $1.133 \mathrm{~kg} / \mathrm{ha}$ de proteína $\Theta 407 \mathrm{~kg} / \mathrm{ha}$ de óleo. Esses rendimentos, tanto em proteina quanto em óleo, são inferiores àqueles obtidos por MASCARENHAS et al. (1982) 


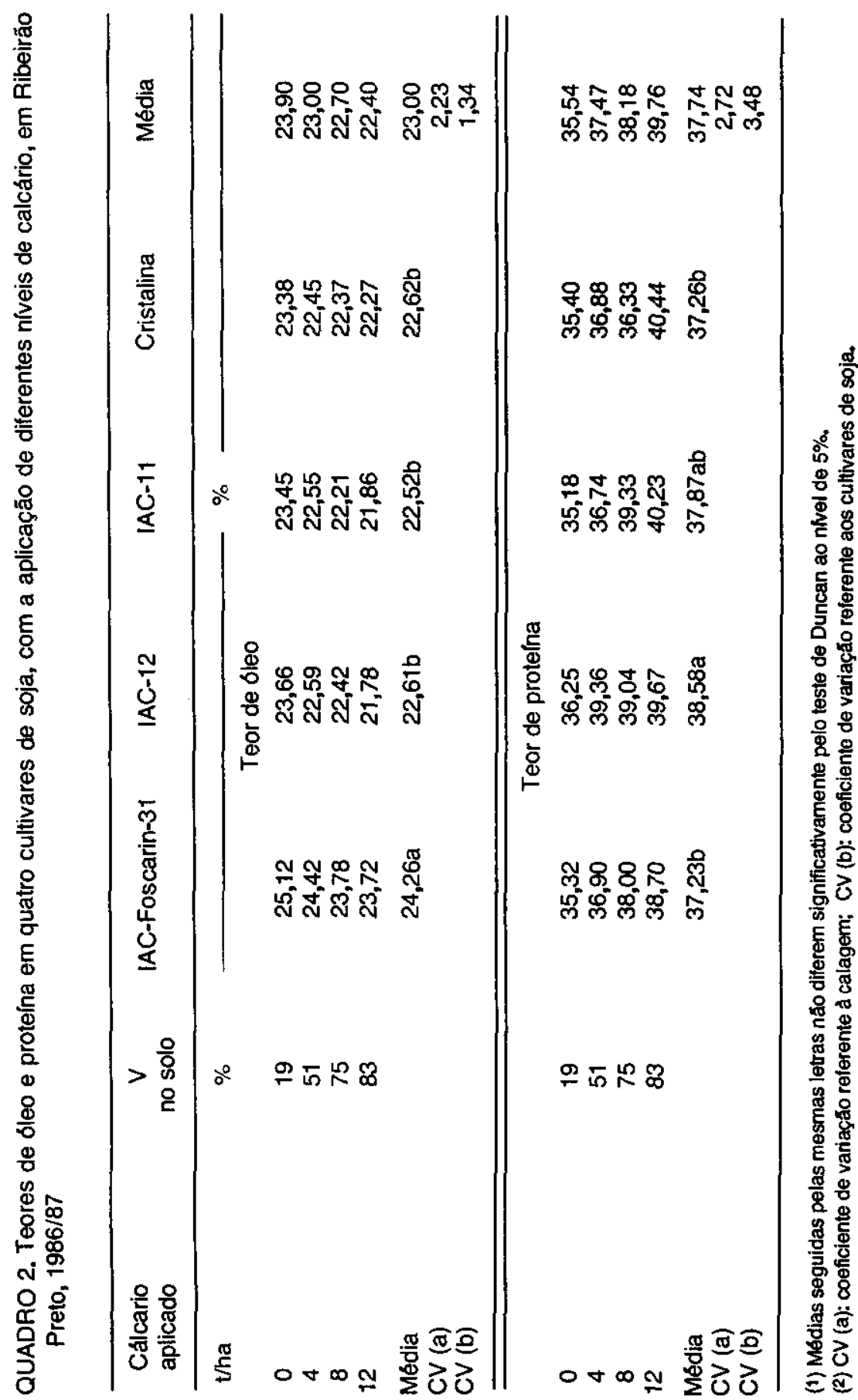


QUADRO 3. Teores médios de proteína e olleo e relação protelna/6́leo dos quatro cultivares de soja, 1986/87

\begin{tabular}{lccc}
\hline Cultivares & Protefna (1) & Óleo (1) & $\begin{array}{c}\text { Relaçăo } \\
\text { proteina/óleo }\end{array}$ \\
\hline & $\%$ & $\%$ & \\
IAC-Foscarin-31 & 37,34 & 24,70 & $1,52: 1,00$ \\
IAC-12 & 38,86 & 23,08 & $1,68: 1,00$ \\
IAC-11 & 38,35 & 23,23 & $1,65: 1,00$ \\
Cristalina & 37,74 & 24,18 & $1,56: 1,00$ \\
\hline
\end{tabular}

(1) Valores médios de Ribeiráo Preto $\theta$ Mococa

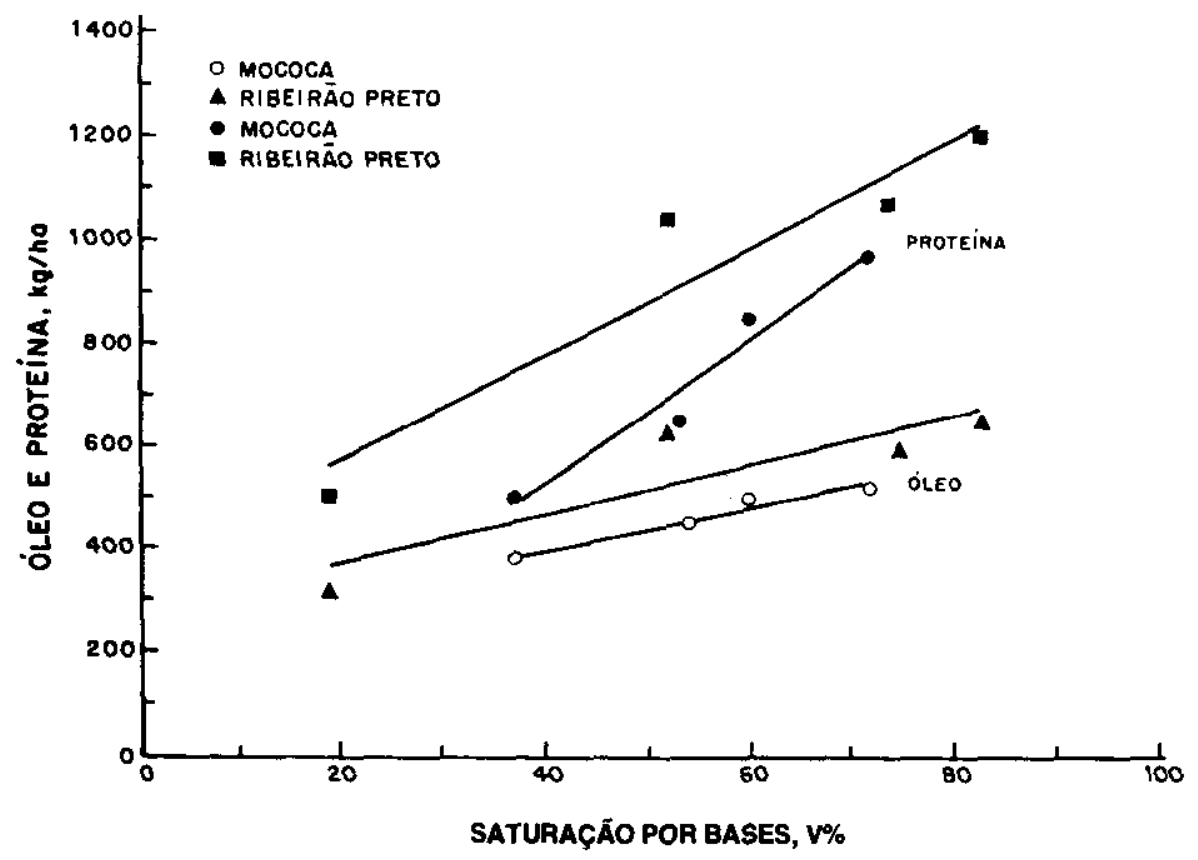

FIGURA 2. Rendimento de óleo e proteína em função do índice de saturação por bases. 


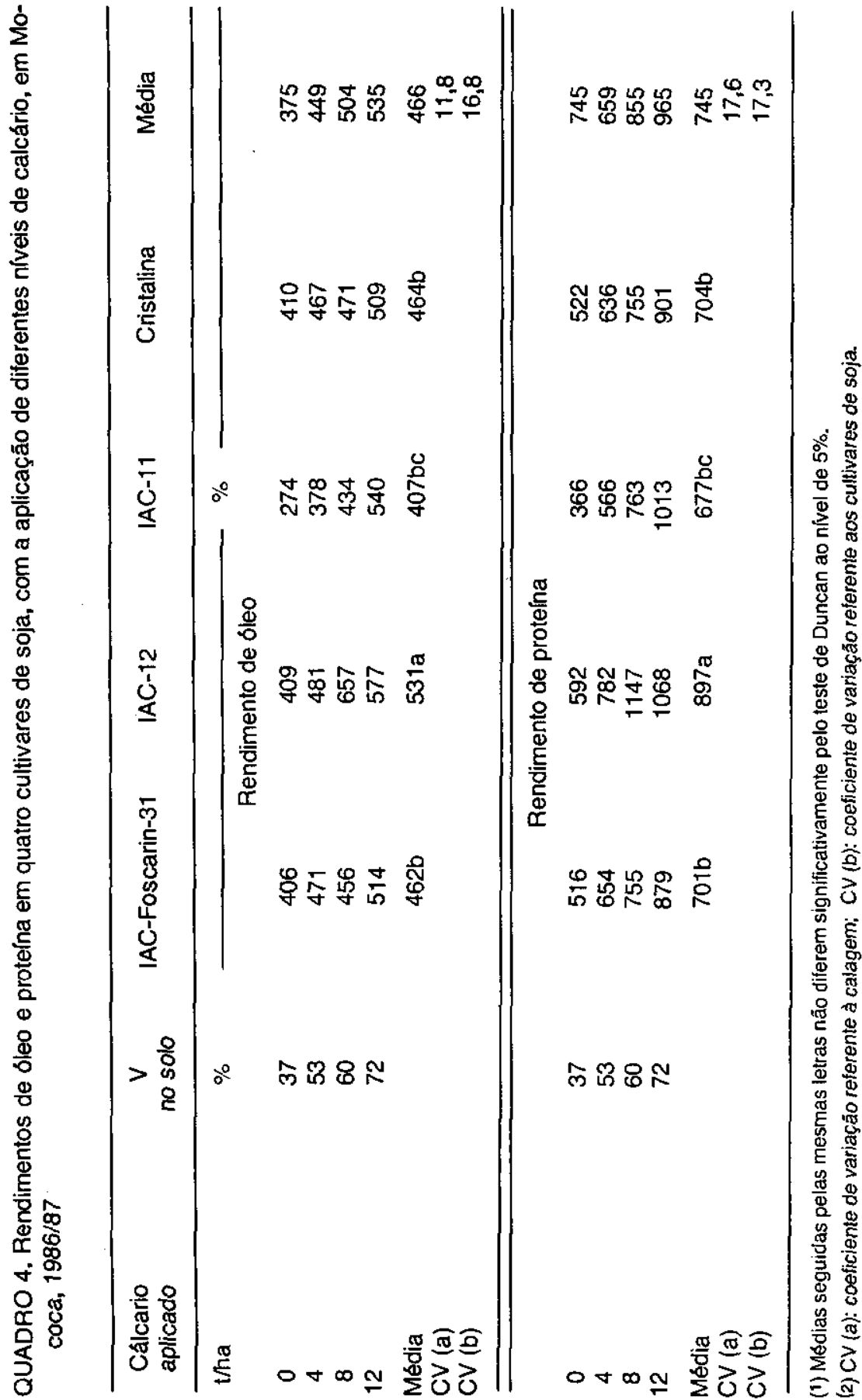




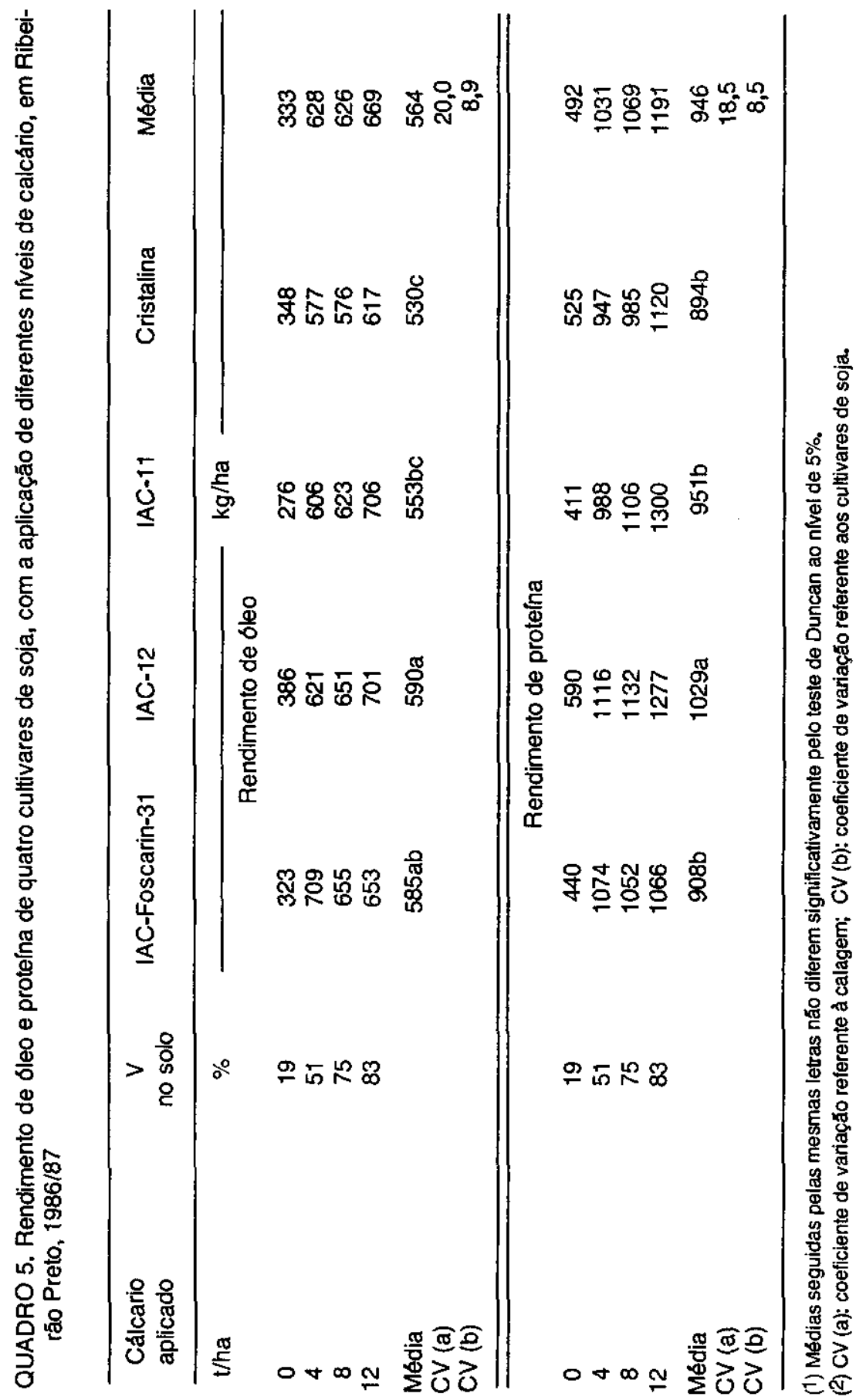


e aos deste estudo para o 'IAC-11' e 'IAC-12' em Ribeiräo Preto, com 12t/ha de calcário. Em Mococa, com a aplicação da mesma quantidade de calcário, os rendimentos de óleo e proteína foram mais baixos (Quadro 4); possivelmente, isso foi devido a um periodo de seca prolongado, adiando a semeadura da soja para 0 início de dezembro. Esse atraso prejudicou o desenvolvimento das plantas e, conseqüentemente, a produtividade dos cultivares.

\section{CONCLUSŌES}

1. Os maiores teores de bleo e proteina foram observados nos grăos colhidos em Moceca.

2. Independentemente da calagem e das localidades, o cultivar IAC-12 apresentou as maiores produtividades médias de óleo e proteína por área, respectivamente, 561 e $963 \mathrm{~kg} / \mathrm{ha}$.

3. Em todas as localidades, a calagem promoveu a elevação do teor de proteína e a redução do teor de óleo nos grảos.

4. Em Ribeirăo Preto, com a aplicaçăo de 12t/ha de calcário, foram obtidos $1.066,1.277,1.300$ e $1.120 \mathrm{~kg} /$ ha de proteina e $653,701,706$ e $617 \mathrm{~kg} / \mathrm{ha}$ de oleo para os cultivares IAC-Foscarin-31, IAC-12, IAC-11 e Cristalina respectivamente.

\section{REFERÊNCIAS BIBLIOGRÁFICAS}

GALLO, P.B.; MASCARENHAS, H.A.A.; QUAGGIO, J.A. \& BATAGLIA, O.C. Resposta diferencial das culturas de soja e sorgo à calagem. Revista Brasileira de Ciência do Solo, Campinas, 10:253-258, 1986.

HARTWIG, E.E. Varietal development. In: SOYBEAN: improvement, production and uses, edited by B.E. Caldwell, R.W. Howell \& H.W. Johnson. Madison, Wis., American Society of Agronomy, 1973. 194p.

HIROMOTO, D.M. \& VELLO, N.A. Genetic base of Brazilian soybean cultivars. Revista Brasileira de Genética, Ribeirăo Preto, 9(2):295-306, 1986.

MAINI, M.S. \& BAINS, G.S. Effect of variety and agronomic practices on the yield and composition of soybeans. Indian Oil Seed Journal, 9(4):231-243, 1965.

MASCARENHAS, H.A.A; QUAGGIO, J.A.; HIROCE, R.; BRAGA, N.R.; MIRANDA, M.A.C. de \& TEIXEIRA, J.P.F. Resposta da soja (Glycine max (L.) Merrill) à aplicaçăo de doses de calcário em solo Latossolo roxo distrófico de cerrado. I. Efeito imediato. In: SEMINÁRIO NACIONAL DE PESQUISA DE SOJA,2., Braslia, 1981. Anais. Londrina, EMBRAPA-CNPSo, 1982. v.2, p.742-751.

MORSE, W.J. Chemical composition of soybean seeds. In: MARKLEY, K.S. Soybeans and soybean products. New York, Interscience, 1959. cap.4, p.135-156. 
PORTO, M.P. Melhoramento para óleo e proteina. In: SOJA: genética e melhoramento, coordenado por Francisco J. Vernetti. Campinas, Fundação Cargill, 1983. p.803-835.

TANGO, J.S.; MASCARENHAS, H.A.A.; FIGUEIREDO, I.B.F. \& SHIROSE, I. Inffuência de anos agricolas sobre os teores de matéria graxa e protelna no grão de soja e ácidos graxos. Coletânea do ITAL, Campinas, 5:345-355, 1974a.

\& _- Influência de localidade de cultura nos teores de matéria graxa e proténa nos grãos de soja e de ácidos graxos no bleo. Coletánea do ITAL, Campinas, 5:339-344, 1974b.

; SHIROSE, I. \& FIGUEIREDO, I.B.F. Influéncia de inoculantes, calagem e adubaçắo química nos teores de matéria graxa e proteína no grăo de soja e de ácidos graxos no oleo. Coletânea do ITAL, Campinas, 5:357-363, $1974 \mathrm{c}$.

TEIXEIRA, J.P.F. Translocaçăo de compostos nitrogenados da planta para os frutos em desenvolvimento $\theta$ acúmulo de substáncias de reserva em grão de soja (Glycine max (L.) Merrill), cultivar Santa Rosa. Campinas, UNICAMP - Instituto de Biologia,1984. 168p. Tese (Mestrado).

; MASCARENHAS, H.A.A. \& BATAGLIA, O.C. Efeito de cultivares, tipos de solo e práticas culturais sobre a composição química de sementes de soja (Glycine max (L.) Merrill). In: SEMINÁRIO NACIONAL DE PESQUISA DE SOJA, 1., Londrina, 1978. Anais. Londrina, EMBRAPA-CNPSo, 1979a. v.1, p.11-16.

; ; MIRANDA, M.C.A. de \& BRAGA, N.R. Efeitos de localidades, adubação e anos consecutivos de plantio sobre o teor de proteinas em sementes de soja cultivar Santa Rosa. Cientfica, Jaboticabal, 7(3):343-346, 19796.

; RAMOS, M.T.B.; MIRANDA, M.A.C. de \& MASCARENHAS, H.A.A. Relaçăo entre os principais constituintes químicos de grāo de soja. In: SEMINÁRIO NACIONAL DE PESQUISA DE SOJA, 3., Campinas, 1984. Anais. Londrina, EMBRAPA-CNPSo, 1984. p.898-908. (EMBRAPA-CNPSo. Documentos, 7) 